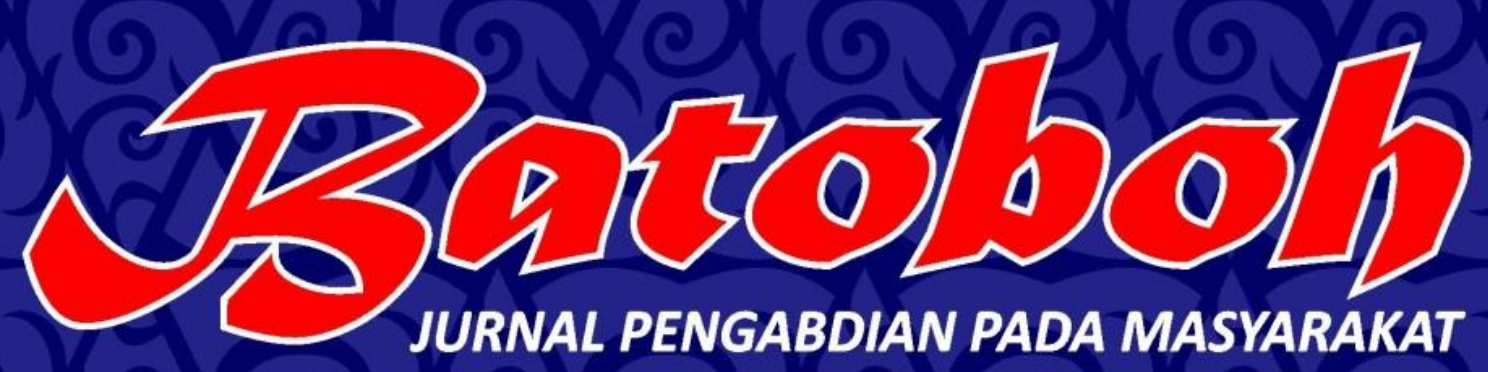

ISSN: 2548-5458

Volume 1

Nomor 2

JURNAL PENGABDIAN PADA MASYARAKAT

Oktober 2016

hlm. 131-266

Yusfil, Zulkifli, Erlinda

PENERAPAN TEKNOLOGI SENI PADA SANGGAR SENI TRADISIONAL

DI KABUPATEN PESISIR SELATAN SUMATERA BARAT

Asril

PELATIHAN LAGU SIONTONG TABANG, KURETA MANDAKI, DAN OYAK TABUIK

PADA GRUP GANDANG TASA ANAK-ANAK, SANGGAR ANAK NAGARI DESA SUNGAI PASAK, KOTA PARIAMAN

Nofrial, Wahyono, Riski Rahmat Kurniawan Dan Alek Hengki Ziora

PEMANFAATAN SERBUK GERGAJI MENJADI PRODUK KERAJINAN DI WAN PERABOT,

TARANTANG KECAMATAN HARAU, 50 KOTA

Dira Herawati, Muhammad Husni, A Nick Koto Agam, Eza Ramadhani

PELATIHAN FOTOGRAFI PADA KEGIATAN EKSTRA KURIKULER DI SMKN 2 PADANGPANJANG

F. X Yatno Karyadi, Eriswan, Bari, Rahmat, Irham

PELATIHAN PEMBUATAN VIDEO DAN FOTO MAKRO MENGGUNAKAN TABLE-TOP STUDIO UNTUK SISWA SMA

Novina Yetri Fatrina, Ediantes, Putri Andam Dewi, Suri Handai Yani

PELATIHAN TEKNIK MEMBUAT RIAS EFEK UNTUK FILM FIKSI PADA SMK 2 PADANGPANJANG

Rosta Minawati, Heri Sasongko, Gilang Febriano, Vini Rusmana

PENGENALAN PRODUKSI FILM DOKUMENTER BAGI SISWA/ SISWI SEKOLAH MENEGAH ATAS

Hafif HR, Fahmi Marh, Ade Sulistiawan, Dino Ashari

PENERAPAN MULTI DISIPLIN SENI DALAM KEGIATAN DRUMBAND PADA EKSTRAKURIKULER SMA 3 PADANGPANJANG

Febri Yulika, Selvi kasman, Putri Khairina Masta

PENINGKATAN KOMPETENSI GURU MELALUI PELATIHAN PENULISAN KARYA TULIS ILMIAH

Darmansyah, Novesar Jamarun, Firdaus, Indra Arifin, Fitra Muhaddis

PELATIHAN INSTRUMEN MUSIK TRADISIONAL MINANGKABAU DI MAN 2 GUNUNG PADANGPANJANG 



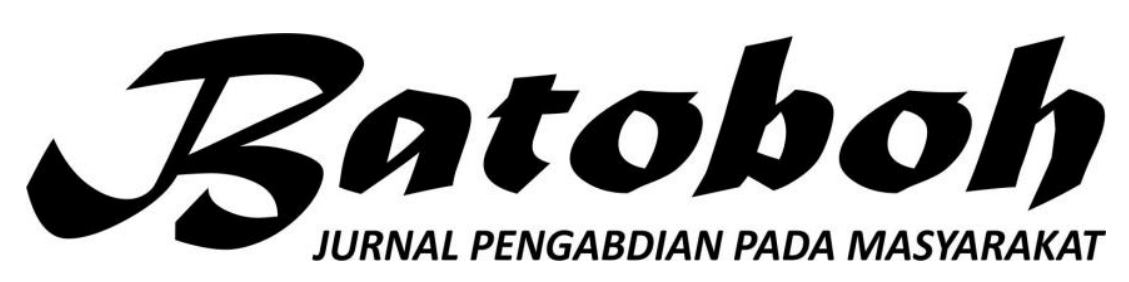

ISSN: 2548-5458 Volume 1, Nomor 2, Oktober 2016, hlm. 131-266

Terbit dua kali setahun pada bulan April dan Oktober. Pengelola Jumal Pengabdian pada Masyarakat merupakan subsistem LPPMPP Institut Seni Indonesia (ISI) Padangpanjang.

\author{
Pengarah \\ Rektor ISIPadangpanjang \\ Penanggung Jawab \\ Kepala Pusat Penerbitan ISI Padangpanjang \\ KetuaPenyunting \\ Andar Indra Sastra \\ Penyunting \\ Asril \\ Sahrul \\ RostaMinawati \\ Harissman \\ Pimpinan Redaksi \\ Saaduddin \\ Redaktur \\ Liza Asriana \\ Rori Dolayance \\ Tata Letak dan Desain Sampul \\ Yoni Sudiani \\ WebJurnal \\ Thegar Risky
}

Alamat Pengelola Jumal Batoboh:LPPMPP ISI Padangpanjang

Jalan Bahder Johan Padangpanjang 27128, Sumatera Barat; Telepon (0752) 82077 Fax. 82803;

e-mail; batoboh@gmail.com

Catatan. Isi/Materi jurnal adalah tanggung jawab Penulis.

Diterbitkan Oleh

Institut Seni Indonesia (ISI) Padangpanjang 


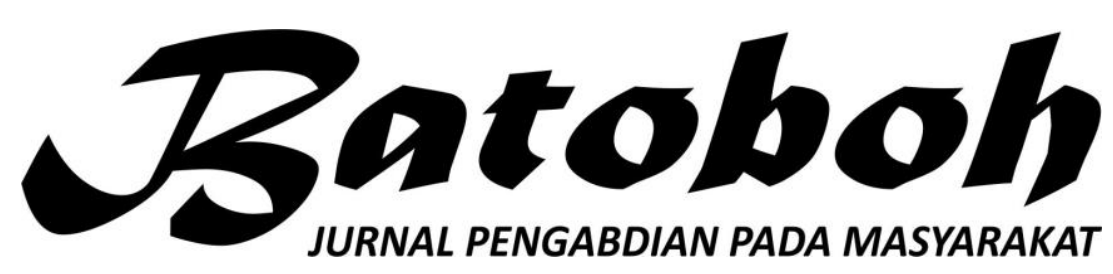

ISSN: 2548-5458 Volume 1, Nomor 2, Oktober 2016, hlm. 131-266

\section{DAFTAR ISI}

\begin{tabular}{|l|l|}
\hline \multicolumn{1}{|c|}{ PENULIS } & \multicolumn{1}{c}{ JUDUL } \\
\hline Yusfil, Zulkifli, Erlinda & $\begin{array}{l}\text { Penerapan Teknologi Seni Pada Sanggar Seni } \\
\text { Tradisional Di Kabupaten Pesisir Selatan Sumatera } \\
\text { Barat }\end{array}$ \\
Asril & $\begin{array}{l}\text { Pelatihan Lagu Siontong Tabang, Kureta Mandaki, } \\
\text { Dan Oyak Tabuik Pada Grup Gandang Tasa Anak- } \\
\text { Anak, Sanggar Anak Nagari Desa Sungai Pasak, } \\
\text { Kota Pariaman }\end{array}$ \\
$\begin{array}{l}\text { Nofrial, Wahyono, Riski } \\
\text { Rahmat Kurniawan Dan } \\
\text { Alek Hengki Ziora }\end{array}$ & $\begin{array}{l}\text { Pemanfaatan Serbuk Gergaji Menjadi Produk } \\
\text { Kerajinan Di Wan Perabot, Tarantang Kecamatan } \\
\text { Harau, 50 Kota }\end{array}$ \\
\hline
\end{tabular}

HALAMAN

Dira Herawati,

Muhammad Husni, A

Nick Koto Agam, Eza

Ramadhani

F. X Yatno Karyadi,

Pelatihan Fotografi Pada Kegiatan Ekstra

Kurikuler Di SMKN 2 Padangpanjang

131-144

$145-164$

Eriswan, Bari, Rahmat, Irham

Novina Yetri Fatrina, Ediantes, Putri Andam Dewi, Suri Handai Yani

Pelatihan Pembuatan Video Dan Foto Makro

190-200 Menggunakan Table-Top Studio Untuk Siswa SMA

Pelatihan Teknik Membuat Rias Efek Untuk Film 201-212 Fiksi Pada SMK 2 Padangpanjang

Rosta Minawati, Heri Sasongko, Gilang

Pengenalan Produksi Film Dokumenter Bagi $213-227$ Febriano, Vini Rusmana

Hafif HR, Fahmi Marh, Ade Sulistiawan, Dino Ashari Siswa/Siswi Sekolah Menegah Atas

$165-181$ 182-189

Febri Yulika, Selvi Kasman, Putri Khairina Masta

Darmansyah, Novesar Jamarun, Firdaus' Indra Arifin, Fitra Muhaddis

Penerapan Multi Disiplin Seni Dalam Kegiatan Drumband Pada Ekstrakurikuler SMA 3 Padangpanjang

Peningkatan Kompetensi Guru Melalui Pelatihan Penulisan Karya Tulis Ilmiah

Pelatihan Instrumen Musik Tradisional $256-266$ Minangkabau Di MAN 2 Gunung Padangpanjang

\footnotetext{
Peraturan Direktur Jenderal Pendidikan Tinggi Kementerian Pendidikan Kebudayaan Republik Indonesia Nomor 1 Tahun 2014 Tanggal Tentang Pedoman Akreditasi Terbitan Berkala Ilmiah. Jumal Batoboh Terbitan Vol. 1, April dan Oktober 2016 Memakaikan Pedoman Akreditasi Berkala Ilmiah Tersebut.
} 


\title{
PENERAPAN TEKNOLOGI SENI PADA SANGGAR SENI TRADISIONAL DI KABUPATEN PESISIR SELATAN SUMATERA BARAT
}

\author{
Yusfil, Zulkifli, Erlinda \\ Prodi Seni Tari \\ Prodi Seni Teater \\ Fakultas Seni Pertunjukan-ISI Padangpanjang \\ Jl. Bahjder Djohan-Padangpanjang. Sumatera Barat \\ yusfiltari@gmail.com \\ zulkifliisipadangpanjang@gmail.com \\ erlindanazir@gmail.com
}

\begin{abstract}
ABSTRAK
Artikel ini berisikan tentang kegiatan IbM Pengabdian Kepada Masyarakat bertujuan untuk membina tiga mitra yaitu, sanggar seni budaya San Alida, Sanggar Legaran Sati, dan sanggar Riak Maampeh yang berlokasi di dua Kecamatan, Kabupaten Pesisir Selatan. Secara khusus untuk menerapkan teknologi seni pada sanggar tersebut tentang artistik pertunjukan Randai, dan Tari dalam bentuk penyuluhan dan pelatihan, dengan memberikan ilmu pengetahuan tentang seni dan tari. Pengembangan gerak secara teknis, untuk dapat dapat dipedomani sanggar sebagai acuan dalam berkreatifitas. Beberapa unsur seni dibidang Randai dan elemen-elemen yang berhubungan dengan tari diuraikan sesuai kebutuhan pertunjukan, agar teknik pengembangan dapat dipelajari sebagai dasar pengembangan yang diharapkan dapat dijadikan acuan oleh sanggar seni yang dibina. Pengabdian ini menggunakan pendekatan partisipatoris dengan metode penyuluhan dan pelatihan. Hasil pengabdian berupa produk karya seni sesuai dengan kebutuhan kemasan pertunjukan.
\end{abstract}

Kata Kunci: seni, Randai, Tari, pembinaan, teknologi seni 


\section{PENDAHULUAN}

Kabupaten Pesisir Selatan merupakan dataran rendah bagian Selatan yang oleh Pemerintahan Belanda disebut Afdeling zwit Benader Lander. Pada tahun 1903, Bandar X dan Kerinci menjadi Afdeling (dataran randahnya) yang pada zaman Belanda dipimpin oleh Asisten Residen (DISPORA BUDPAR: Profil Kabupaten Pesisir Selatan: 2014). Salah satu peninggalan bersejarah Belanda adalah benteng Portugis yang terdapat di Painan. Saat ini benteng tersebut hanya tinggal pintu gerbang yang tidak terawat. Dari peninggalan bersejarah ini muncul istilah untuk pemberian nama Mesjid oleh Bupati, Darizal Basir di daerah Sago yaitu San laida. Demikian juga nama salah satu sanggar yang diberi nama San Alida sebagai mitra pengabdian saat ini. Nama San Laida atau San Alida memiliki sejarah panjang tentang wanita Portugis yang cantik (Wawancara dengan Bahtiar, 16 April 2015 di Salido). Dengan kondisi geografis tersebut, Pesisir Selatan menjadi salah satu daerah tujuan wisata di Sumatera Barat yang menawarkan panorama alam yang indah dan destinasi wisata yang eksotik. Daya tarik alam inilah yang menjadikan Pesisir Selatan sebagai salah satu tempat favorit para wisatawan domestik dan mancanegara yang sengaja datang untuk menikmati keindahan pantai atau keindahan kota Painan sambil terjun layang dari puncak bukit Langkisau. Sebuah iven seni berskala nasional pun telah menjadi agenda wisata tahunan daerah Pesisir Selatan yang dikenal dengan Festival Langkisau.

Pada festival ini ditampilkan beragam kesenian seperti; musik, tari, lagu dan Randai. Untuk penyelenggaraan festival tersebut sejak tahun 2014,pemerintah daerah telah membangun sebuah pentas pertunjukan dengan dana milyaran di Pantai Carocok sebagai tempat berkreatifitas bagi para seniman, sekaligus sebagai media bagi berkembangnya ragam kesenian tradisi yang selama ini jarang dipertunjukkan. Hal seperti ini memberi peluang bagi kesenian tradisi yang dikelola oleh sanggar-sanggar seni untuk dapat tumbuh dan berkembang. Dengan kondisi tersebut, sudah selayaknya masyarakatlokal dengan kesenian mereka ikut merasakan dampak dari industri 
pengembangan pariwisata dengan ikut terdapat di Kecamatan IV Jurai. Oleh berperan serta dalam kepariwisataan. karena sanggar Riak Maampeh yang

Terkait dengan hal di atas yang berlokasi di Pasar Baru Kecamatan berawal dari sebuah pengamatan pada Bayang yang juga membutuhkan Festival Langkisau bulan April 2015, pembinaan, maka juga ikut dibina tim pengabdian tergerak untuk sebagai rasa kepedulian sosial dan rasa melaksakan pembinaan pada sanggar- kekeluargaan.

sanggar untuk menerapkan teknologi seni. Pada Festival Langkisau tersebut, tampil beragam seni pertunjukan

\section{Analisis Situasi}

seperti randai, rebab, tari yang diikuti

Berangkat dari salah satu oleh berbagai sanggar seni dari tiapkegiatan pelatihan produksi seni tiap kecamatan yang antusias untuk yang terdapat di Kabupaten Pesisir menunjukkan kebolehannya di ajang Selatan, atas undangan dari Dinas festival. Namun penampilan seni Pendidikan dan Kebudayaan tangga 4 pertunjukan yang disajikan dari s/d 7 Maret 2016, berdampak positif sebahagian sanggar yang tampil setiap untuk kemajuan sanggar-sanggar, yang tahunnya, kurang mendapat respon selama ini tidak pernah mendapat yang baik dari berbagai kalangan, perhatian dari pemerintah daerah terutama untuk dilombakan. Secara (wawancara dengan Irfan/ Kasi dan keseluruhan masih banyak terdapat Film : .1 Maret 2016). Dalam hal ini kekurangan dalam segi artistik tim dari Institut Seni Indonesia pertunjukan. Hal tersebut tentunya Padangpanjang (Yusfil, Rasmida, tidak membawa kontribusi dari aspek Adjuoktoza, Nirwana Murni) pinansial pada sanggar. Dengan alasan termotifasi untuk memberi pengetahuan tersebut perlu dilakukan pembinaan bagaimana cara mengembangkan tari terhadap sanggar. Berdasarkan banyak tradisional, dan memproduksi seni permintaan dari sanggar-sanggar yang pertunjukan secara profesional, ada, maka dipilih dua diantaranya, yaitu sekaligus bagaimana cara mengelola sanggar Seni dan Budaya San Alida sanggar sesuai dengan perkembangan dan sanggar Seni Legaran Sati yang teknologi saat ini. Pembinaan dan 
pelatihan yang dilakukan selama tiga hari menunjukkan antusiasnya seniman-seniman tradisi untuk meragakan gerak yang sudah dikembangkan di Aula Dinas Pendidikan dan Kebudayaan Painan Kabupaten Pesisir Selatan, seperti foto di bawah ini

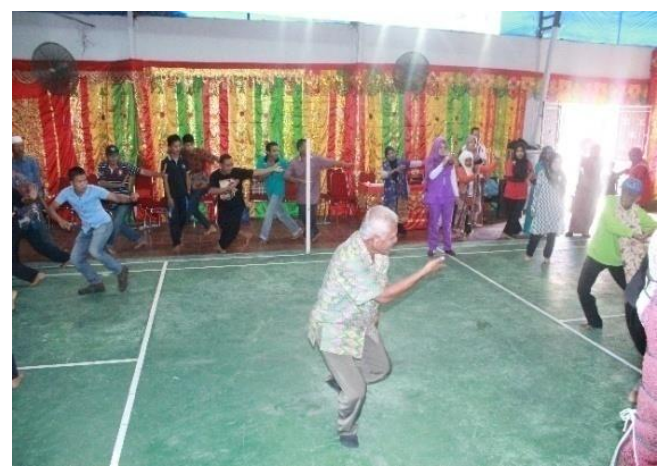

Gambar 1.

Seniman tradisi antusias mergakan gerak yang telah dikembangkan yang berangkat dari gerak tari tradisi miliki masyarakat setempat. (Dok: Yusfil Maret 2016).

Terkait dengan permasalahan mitra yang menjadi skala prioritas untuk dibina pada program IbM ini, maka Sanggar Seni dan Budaya "San Alida" yang terdapat di nagariRawang, sanggar seni Legaran Sati yang terdapat di Painan, dan sanggar Riak Maampehadalah tiga sanggar seni budaya yang sangat membutuhkan pembinaan dari tim pengabdian kepada masyarakat. Hal ini berhubungan dengan maraknya iven Festival
Langkisau tiap tahun yang selalu mengadakan lomba kesenian antar daerah dan tingginya permintaan akan pertunjukan kesenian tradisional masyarakat Pesisir Selatan. Ketiga sanggar ini berharap mendapat pembinaan tentang Randai dan tari.Di samping itu berharap untuk mendapatkan pengetahuan tata artistik pertunjukan, karena seni yang dimilikiberpotensial untuk dibina, agar berdampak ekonomi bagi sanggar.

Sebagaimana permasalahan mitra yang berkeinginan untuk dibina perlu diwujudkan dengan keberagaman kesenian yang dimilikiseperti; randai dan tari-tarian. Randai dan tari-tarian potensi untuk dikembangkan dengan menerapkan teknologi seni tanpa meninggalkan nilai-nilai yang melekat pada kesenian tradisi tersebut.

Dilatarbelakangi oleh kondisi ketiga sanggar yang membutuhkan pembinaan dibidang seni, terutama dalam mengemas sebuah pertunjukan, menjadi perhatian khusus untuk melakukan pengabdian kepada masyarakat. Para remaja yang ada akan difungsikan untuk berkesenian terutama memahami Randai dan Tari. Untuk Randai akan dilatihkan teknik 
bermain randai dengan tapuak Agar kerjasama berjalan dengan galembong-nya sebagai daya tarik baik, maka anggota tim pengabdian tersendiri pada pertunjukan randai, kepada masyarakat memprogramkan demikian juga dengan teknik menari sistem pelatihan maupun workshop dan dialog maupun unsur-unsur yang kesenian setiap hari Sabtu dan Minggu, terkait dengan pertunjukan Randai. dengan memberikan pengetahuan seni

Di samping itu, di kecamatan IV dengan teknologinya, termasuk Jurai terkenal dengan tari rantak kudo bagaimana cara mengelola sebuah yang telah banyak diteliti. Nampaknya sanggar sesuai dengan ilmu tari rantak kudo dapat dikembangkan manajemen. Hal seperti ini akan dan dilatih kepada anggota sanggar berlanjut terus sesuai waktu, dan dana dengan menerapkan konsep koregrafi yang tersedia serta dilandasi oleh sebagaimana yang dijelaskan Alma kesediaan kerjasama sanggar yang akan Hawkin dalam Sri Rochana bahwa dibina dengan tim pengabdian kepada konsep koreografi merupakan masyarakat, termasuk kerjasama pemikiran-pemikiran yang diterapkan dengan Pemerintah Daerah Setempat. untuk mewujudkan suatu bentuk dan gaya suatu tata susunan tari, sementara bentuk itu sendiri merupakan salah satu prinsip dasar dari koreografi yang hadir sebagai suatu organisasi kekuatan dari hasil struktur internal dalam tari (2014: 3). Pengembangan pola-pola geraksesuai dengan kaedah-kaedah sebuah koreografi tanpa menghilangkan nilai-nilai yang melekat pada tari rantak kudo itu sendiri agar karakteristiknya tetap terjaga. Dengan demikian tari rantak kudo akan produktif dan akan selalu eksis di tengah masyarakat.

\section{HASIL DAN PEMBAHASAN}

\section{A. Teknis di Lapangan}

Dewasa ini pemahaman terhadap kesenian tradisional bagi generasi muda dianggap sesuatu yang sudah ketinggalan zaman dan telah tertinggal oleh arus informasi dan teknologi, sementara kesenian tradisional potensi untuk digali dan dikembangkan sebaik mungkin sebagai cerminan indentitas budaya. Oleh sebab itu perlu dilakukan pembinaan melalui pengabdian kepada masyarakat agar 
kesenian tradisonal tetap lestari bagi sanggar-sanggar yang ada, terutama pada tiga sanggar yang akan dibina.

Pembinaan terkait dengan maraknya iven pertunjukan, seperti Festival langkisau yang setiap tahun selalu diadakan oleh Pemerintah Daerah setempat dengan berbagai kegiatan lomba seni, baik tari maupun musik, randai, cerdas budaya dan lain sebagainya.

Dari hasil pembinaan produksi seni pertunjukan tanggal 4 s.d 7 Maret, semua sanggar berharap agar kegiatan tersebut tetap berlanjut. Akan tetapi tentu ada skala prioritas untuk dibina sesuai situasi dan kondisi, serta jarak tempuh yang perlu dipertimbangan. Sejalan dengan harapan sanggar, tim pengabdian pada masyarakat dari Institut Seni Indonesia Padangpanjang yang didanai oleh DIKTI antusias untuk membinanya atas kesepakatan kerjasama yang telah dibuat. Walaupun ditetapkan dua mitra yang menjadi targetpengabdian, tetapi tidak menutup kemungkinan bagi sanggar -sanggar yang berminat diberi peluang untuk ikut serta seperti sanggar Riak Maampeh yang terdapat di daerah Pasar Baru, kecamatan Bayang.
Kegiatan pengabdian dalam bentuk penerapan teknologi seni yang sangat diperlukan oleh mitra sebagai sanggar seni di Pesisir Selatan dapat memenuhi target dan luaran yang diharapkan. Penerapan teknologi seni yang dimaksud adalah bagaimana mentransfer pengetahuan dan keterampilan dibidang seni dalam bentuk penyuluhan dan pelatihan, sehingga dapat memberdayakan potensi seni tradisi yang dimiliki oleh mitra dengan tujuan;

1. Terwujudnya Kualitas Artistik Penyajian.

Untuk meningkatkan mutu sebuah penyajian seni,terutama randai dan tari dibutuhkan pengetahuan tentang pengetahuan artistik pertunjukan yang terkait dengan masalah bentuk dan teknik. Masalah bentuk dan teknik meliputikemasan pertunjukan yang layak dan dapat dinikmati oleh berbagai kalangan sebagai tontonan yang menarik. Untuk itu perlu pembinaan tentang masalah tersebut agar ragam kesenian yang dimiliki seperti tari dan randai benar-benar 
berkembang dan dapat Berangkat dari permasalahan meningkatkan kualitas penyajiannya. mitra dan tujuandi atas, maka metode

2. Terwujudnya Manajemen Sanggar pelaksanaan yang dikembangkan yang efektif dan efisien

Pengelolaan tentang sanggar perlu yang sifatnya partisipatoris. ditingkatkan dengan Keterlibatan yang partisipatif, bukan memberdayakan anggotanya untuk saja dari pihak tim yang terlibat dalam memahami pengetahuan tentang aktivitas pengabdian kepada manajemen. Pengetahuan masyarakat, tetapi juga masyarakat manajemen yang akan diberikan setempat sebagai stake-holder termasuk menyangkut tentang organisasi alumni ASKI, STSI maupun ISI sanggar, mengemas paket-paket Padangpanjang, sehingga nantinya pertunjukan sesuai dengan kondisi kegiatan pengabdian dapat memenuhi pertunjukan. target dan luaran yang diharapkan.

3. Menghasilkan Produksi Seni Sanggar dengan kesenian Pertunjukan. tradisionalnya, apabila dibina dengan Dalam memproduksi sebuah penerapan teknologi seni, maka akan pertunjukan, diperlukan sumber bernilai ekonomi bagi sanggar daya manusia yang potensial untuk bersangkutan. Dalam hal ini dicoba menghasilkan kualitas pertunjukan. membinanya dengan menggunakan Untuk itu akan diberikan pengetahun metode pengembangan yang dalam bagaimana cara memproduksi penelitian dikenal dengan metode R\&D sebuah pertunjukan dengan (Researh and Development). Metode memberdayakan para anggotanya. ini adalah metode penelitian yang Tujuannya agar sanggar bisa mandiri digunakan untuk menghasilkan produk dalam hal menghasilkan bentuk- tertentu dan menguji keefektifan bentuk produksi baru baik randai produk tersebut (Sugiyono, 2008: 297). maupun tari tanpa campur tangan Dengan metode ini memberikan pihak lain, sehinggalahir seni kesempatan kepada sanggar untuk pertunjukan yang menjadi ciri dapat tampil dalam berbagai iven, dan sanggar bersangkutan. 
akan berdampak terhadap SDM dari aspek finansial.

Teknik pelaksanaan, adalah penyuluhan/ceramah, demonstrasi dan pelatihan tentang teknologi seni pada sanggar sebagai mitra pengabdian terhadap randai dan tari yaitu, sanggar Seni Budaya San Alida, sanggar Legaran Sati, dan sanggar Riak Maampeh. Tahap-tahap yang akan dilakukan dalam kegiatan pengabdian kepada masyarakat adalah sebagi berikut.

\section{Penyuluhan/Ceramah}

Melakukan ceramah tentang teknologi seni terkait dengan artisitk pertunjukan, manajemen pertunjukan, dan produksi pertunjukan. Penyuluhan/ cermah dilakukan kepada mitra agar mereka memiliki pengetahuan tentang mengemas sebuah pertunjukan secara artistik terkeloa dengan baik, dan dapat dikembangkan sesuai dengan kondisi kekinian. Dalam hal ini semua anggota sanggar atau yang mewakili dikumpulkan pada suatu tempat, yaitu di Aula Dinas Pendidikan dan Kebudayaan atas izin dari Kasi dan Film. Kerjasama ini akan berdampak positif atas keberlanjutan pengabdian dimasa yang akan datang. Dalam hal ini diucapkan terimakasih kepada bapak Irfan selaku Kasi dan Film Dinas Pendidikan dan Kebudayaan Pesisir Selatan dan beberapa orang anggotanya yang tidak dapat disebutkan satu persatu yang telah memfasilitasi pengabdian berupa ruangan tempat latihan. Demikian juga ucapan terimakasih kepada wali nagari Pasar Baru yang juga memfasilitasi tim untuk memotifasi anggota sanggar agar selalu datang tepat waktu selama pengabdian berlangsung. Diharapakan kerjasama seperti ini tetap eksis dimasa yang akan datang. Tidak dapat dipungkiri, terlaksananya pengabdian ini adalah antusianya dan kedekatan para anggota sanggar dengan tim, terutama pembina sanggar, untuk itu diucapkan terimakasih, semoga apa yang telah diterapkan bermanfaat dimasa yang akan datang.

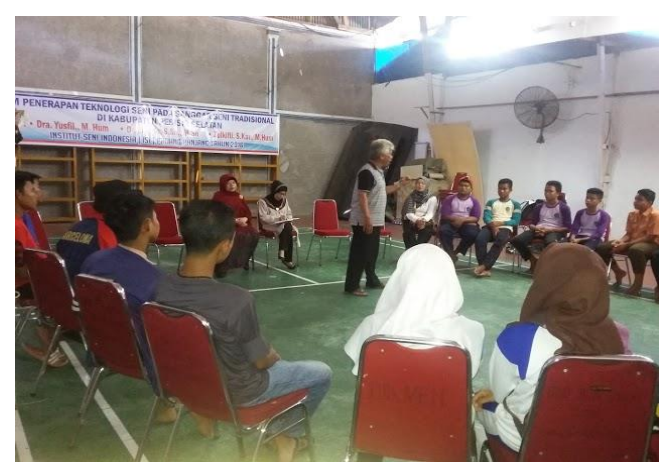

Gambar 2. 
Peretmuan pertama dengan memberikan pejlesanatentang tujuan dan manfaat pengabdian khusunya tentang teknologi seni kepada mitra, bertempat di Aula Dinas Pendidikan dan Kebudayaan Painan Kabupaten Pesisir Selatan, Sabtu: 26 Maret 2016

Kegiatan pengabdian baik berupa ceramah maupun demonstrasi berlanjut secara intensif pada hari Sabtu dan hari Minggu setiap bulan untuk memberi solusi yang tepat sesuai dengan permasalahan dan kebutuhan yang diinginkan mitra.

\section{Pelatihan/Demonstrasi}

Pelatihan dilakukan dalam bentuk workshop pertunjukan, worshop manajemen pertunjukan, dan worshop artisitik pertunjukan. Worshop pertunjukan dalam bentuk randai dan tari, worshop manajeman dalam bentuk pengelolan kelompok sanggar, sedangkan worshop seni pertunjukan difokuskan pada artistik pertunjukan terkait dengan estetika penyajian randai dan tari. Dalam hal ini tim pengabdian pada tahap awal membekali sanggar untuk memahami sejarah Randai dan etika permainan Randai, demikian juga masalah dialog atau semua yang terkait dengan pertunjukan Randai. Di samping itu bagaimana cara mengembangkan tari tradisi yang dimiliki sanggar, sesuai dengan perkembangan teknologi saat sekarang.

\section{Diskusi}

Sebagaimana metode penyuluhan dalam bentuk ceramah yang telah diterapkan tentang penerapan teknologi seni kepada mitra yang dibina, maka diskusipun dilakukan, agar mitra tidak jenuh untuk mendengarnya. Untuk itu dilakukan diskusi.

Diskusi dilakukan untuk mengapresiasi anggota agar tidak menjadi pendengar yang pasif. Dalam hal ini dapat dikatakan semua anggota antusias dan termotifasi untuk berkreatifitas dimasa yang akan datang.

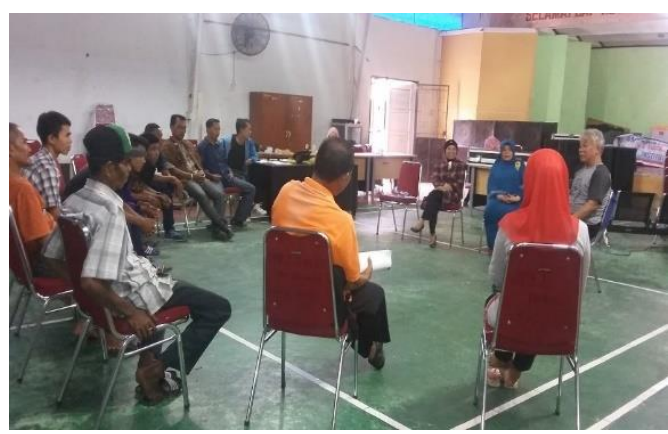

\section{Gambar 3.}

Diskusi dengan anggota sanggar tentang pemahaman teknologi seni untuk artistik pertunjukan Randai dan Tari, bertempat di Aula Dinas Pendidikan dan Kebudayaan, Painan Kabupaten Pesisir Selatan, Minggu: $15 \mathrm{Mei}$ 2016 


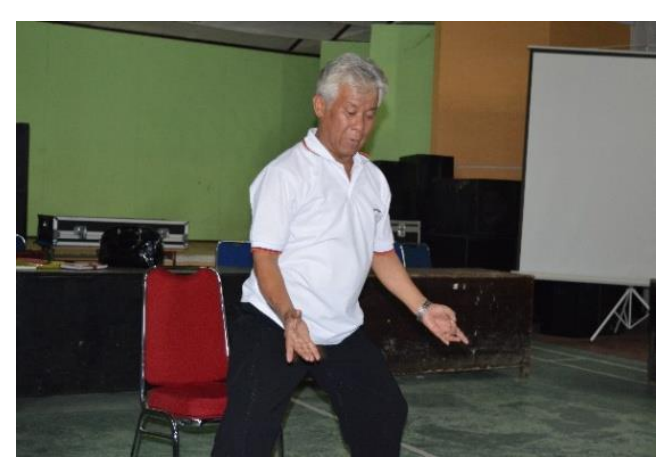

Gambar 4.

Diskusi dan meragakan teknik gerak sebagai bentuk, pengembangan tari tradisi, hari Sabtu 25 Juni 2016

\section{B. Pengamatan Pertunjukan Randai}

Pengamatan merupakan salah satu usaha untuk mengevaluasi kelebihan dan kekurangan suatu pertunjukan, khususnya pertunjukan Randai. Hal ini sesuai permintaan sanggar Riak mampeh. Pengamtan ini dihadiri oleh seniman-seniman tradisi. Hasil dari pengamatan akan diapresiasi yang kemudian dievaluasi.

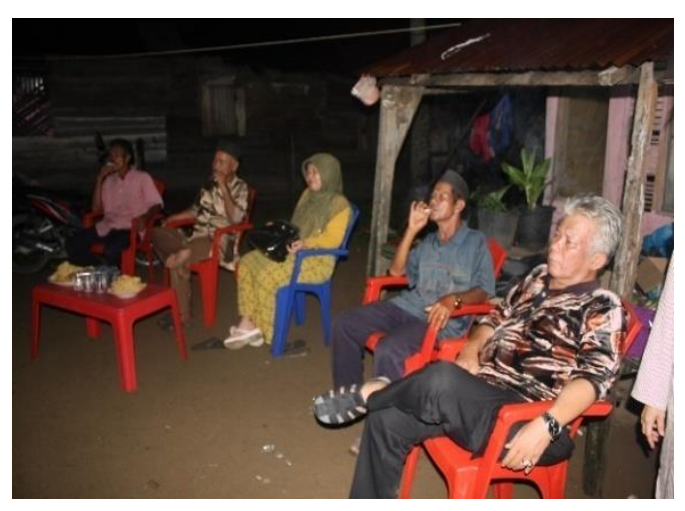

Gambar 5.

Mengamati pertunjukan Randai oleh sanggar Riak Maampehyang dihadiri oleh seniman Randai, Sabtu: 21 Mei 2016.
Pertunjukan Randai yang disajikan secara utuh oleh sanggar Riak Maampeh merupakan pertunjukan yang selalu dilombakan pada Festival Langkisau, tetapi tidak mendapat nominasi (wawancara dengan pelatih sanggar, Nel). Secara cermat tim mencoba memahami pertunjukan yang telah disajikan, kemudian menjelaskan dan mengevaluasinya terkait dengan unsur-unsur Randai seperti dialog, akting, gerak langkah, kostum maupun rias.

Pengamatan pertunjukan Randai dilakukan untuk mengetahui bentuk penyajiannya secara utuh oleh sanggar Riak Maampeh. Hal ini bertujuan untuk mengapresiasi anggota dalam memahami etika dan estetika pertunjukan yang sesungguhnya jika memang terdapat hal-hal yang menunjukkan ketidak sesuaian dengan etika dan estetika, serta artistik pertunjukan yang sesungguhnya. Dalam hal ini semua anggota sanggar tampil secara utuh sesuai dengan apa yang telah disajikannya pada Festival Langikau bulan April 2016 di Painan.

Dari hasil pengamatan banyak hal yang perlu dipahami anggota sanggar, baik dari aspek teknik dialog, 
kostum, tapuak galembong, dan bentuk penyajiannya. Tim pengabdian, memberi pengetahuan tentang sejarah Randai, dan perkembangan Randai di Minangkabau, demikian juga tentang teknik bermain Randai. Di sisi lain masalah kostum Bundo Kanduang kurang tepat dipakai oleh seorang pendendang, walaupun sudah dikreasikan. Sebaiknya pendendang tidak memakai kostum bundo kanduang, karena bundo kanduang/ sebagai orang tua di Minangkabau adalah pemilik kesenian tradisional dan bukan sebagai pelaku. Demikian nilai yangmelekat pada Bundo Kanduang yang kostumnya dipakai oleh seorang pendendang seperti terlihat pada foto di bawah ini.

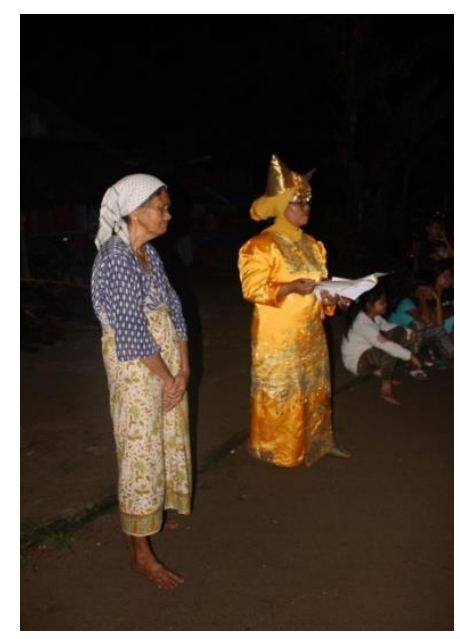

Gambar 6.

Pendendang, memakai kostum Bundo Kanduang untuk pertunjukan Randai bersama seorang nenek yang antusias menonton pertunjukan, Sabtu: 21 Mei 2016
Setelah pengamatan selesai, tim memberikan arahan dan pemahaman tentang unsur-unsur Randai sesuai dengan artistik pertunjukan yang berlangsung saat ini. Selain dari kostum Bundo kanduang yang kurang tepat dipakai oleh pendendang, maka unsurunsur dialog juga menjadi pertimbangan untuk memahami nilainilai yang terkandung di dalamnya. Seperti kata-kata mano sagalo ninik mamak..... yang diucapkan oleh seorang keponakan juga kurang tepat. Sebaiknya langsung saja diucapkan ninik mamak......, kata-kata mano sagalo ini biasanya digunakan bagi yang sepantar dengan pembicara atau di bawah usi sipembicara. Selain itu juga diberikan pengetahuan tentang akting-akting pemeran dalam Randai.

Oleh karena hari semakin larut malam, maka minggu-minggu selanjutnya diberi pelatihan tentang Randai, seperti foto di bawah ini.

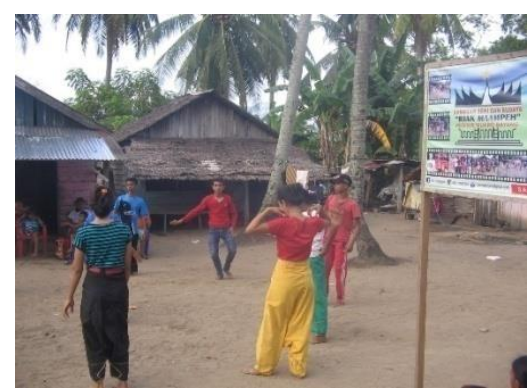

Gambar 7.

Latihan legaran untuk Randai pada sanggar Riak Maampeh 
Ketika tim reviuwer internal merupakan moment yang tepat bagi tim datang, sanggar Riak Maampeh pengabdian untuk menghasikan sebuah Antusias untuk menampilkan karya Tari Bebasis Randai sebagai tema kebolehannya di pinggir pantai sebagai Festival yang diadakan pada bulan lokasi sanggar Riak Maampeh. Hal ini Agustus 2016 di Aula Taman Budaya. mendapat respon positif dari wali Festival ini dikhususkan untuk sanggarnagari Pasar baru seperti foto di bawah ini.

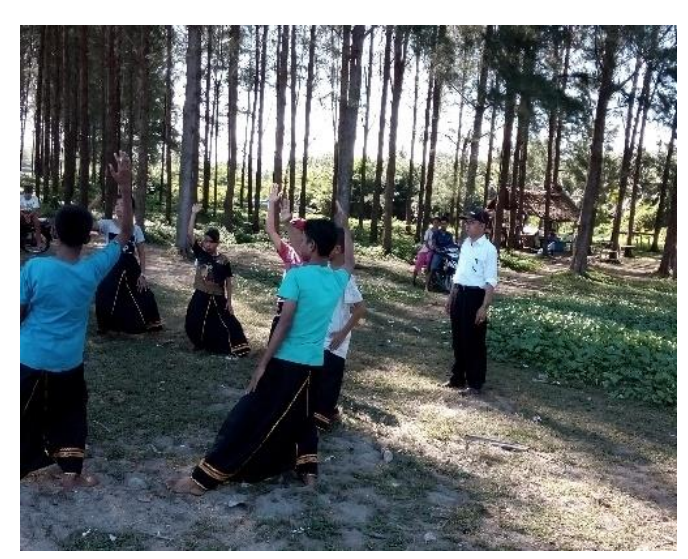

Gambar 8.

Kunjungan Reviewer internal. Dr. Ediwar, ke lokasi Pengabdian, 16 Agustus 2016

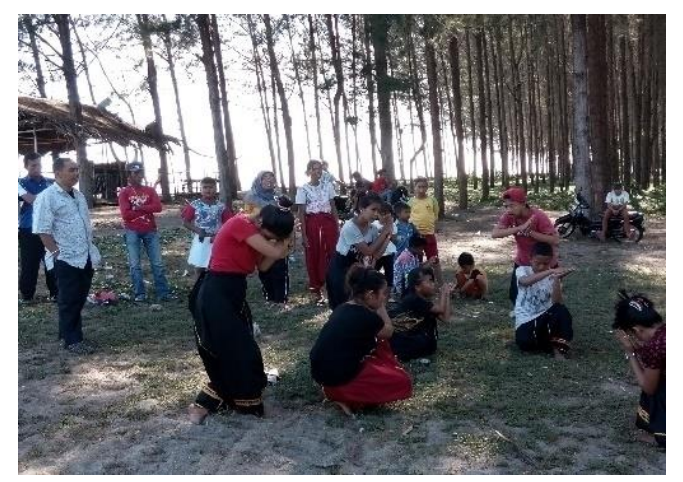

Gambar 9.

Kunjungan Reviewer internal. Dr. Syahrul ke lokasi Pengabdian, 16 Agustus 2016

\section{Produksi Tari Berbasis Randai}

Taman Budaya Padang sebagai

ajang berkreatifitas bagi masyarakat, sanggar yang ada di Sumatera Barat. Dalam hal ini sanggar San Alida dan sanggar Legaran Sati dilatih untuk menghasilkan sebuah karya. Oleh tim pengabdian karya ini diberi judul Langkah Salayang.

Garapan berdurasi tujuh menit ini menerapkan unsur-unsur Randai dengan pengembangan gerak-gerak tari Benten dan tari Rantak Kudo sebagai tari milik masyarakat setempat.

Festival Tari Berbasis Randai yang pertama kali diprogramkan oleh Taman Budaya Padang tahun 2016, meruapakan momen yang tepat bagi sanggar untuk mendapatkan pembinaan dan pelatihan. Sehingga, pengabdian yang dilakukan berdampak positif bagi Sanggar. Hal ini dibuktikan oleh sanggar San Alida dan sanggar Legaran Sati untuk tampil dalam Festival Tari Berbasis Randai di Taman Budaya Padang, pada tanggal 15 September 2016 


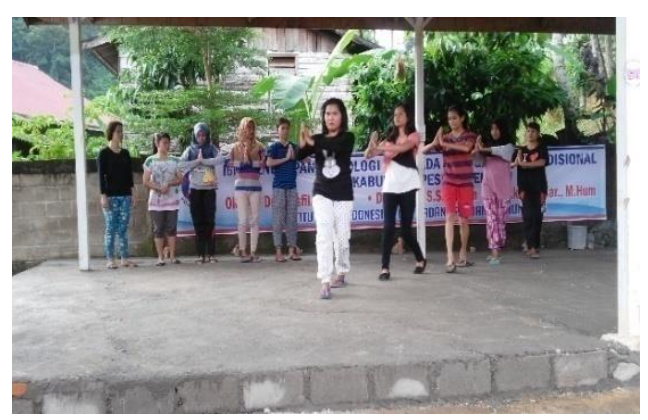

Gambar 10.

Latihan Tari Berbasis Randai yang diawali dengan gerak sembah pada sanggara San Alida dan sanggar Legaran Sati

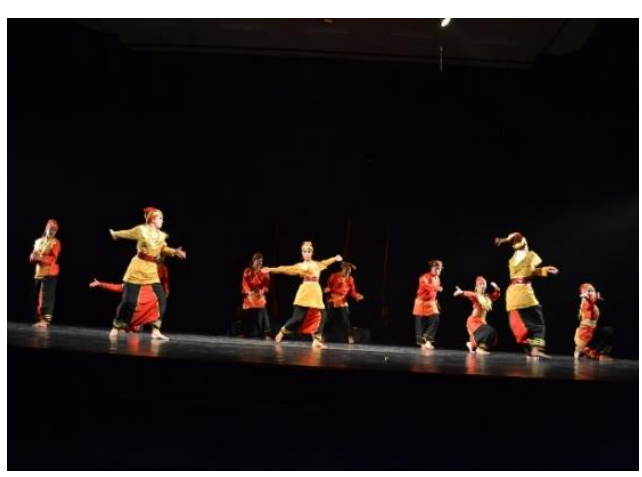

Gambar 11.

Pertunjukan tariLangkah Salayang oleh sanggar San Alida dan sanggar Legaran Sati pada Festival Tari Berbasisi Randai di Taman Budaya Padang, tnggal 16 September 2016

(Dokumentasi: Toni)

\section{KESIMPULAN}

Sebagaimana tujuan pengabdian kepada masyarakat yang diinginkan, berjalan sesuai dengan harapan, karena minat anggota untuk mengapresiasi kegiatan sangat tinggi. Demikian juga dengan dukungan dari Dinas Pendidikan dan Kebudayan Painan berupaya memfasilitasi kegiatan. Beberapa alumni yang berpartisipasi dalam pengabdian juga antusias untuk keberlangsungan pengabdian, dan berharap agar pengabdian tetap ada setiap tahunnya. Sebagaimana harapan yang diinginkan mitra, sanggar Seni dan Budaya San Alida percaya diri dapat tampil pada Festival Tari Berbasis Randai yang dilaksanakan oleh Taman Budaya Padang, hari Sabtu, 16 September 2016. Hal ini didukung saran dan pengetehuan untuk memproduksi pertunjukan yang diberikan.

Diharapkan hasil dari pengabdian kepada masyarakat ini dapat bermanfaat dan selalu diapresiasi masyarakat Pesisir Selatan, khususnya oleh Sanggar-sanggar lainnya di Kabupaten Pesisir Selatan. Demikian juga Dinas Pendidikan dan Kebudayaan untuk selalu eksis dalam mengembangkan potensi seni tradisional yang ada di Pesisir Selatan. Diharapkan juga kepada lembaga ISI Padangpanjang dapat memfasilitasi keberlanjutan pengabdian kepada masyarakat di Pesisir Selatan setiap tahunnya. 


\section{KEPUSTAKAAN}

DISPORA

BUDPAR:

Profil

Kabupaten Pesisir Selatan: 2014).

Sugiyono. 2008. Metode Penelitian Kuantitatif, Kualitatif dan $R$ \& $D$. Bandung: Alfabeta.
Sri Rochana Widyastutieningrum, Dwi Wahyudiarto. 2014. Pengantar Koreografi.

Zulkifli. 1993. "Randai Sebagai Teater Rakyat Minangkabau di Sumatera Barat: Dalam Dimensi Sosial Budaya" (Tesis). Yogyakarta: UGM.

\section{POSTER}

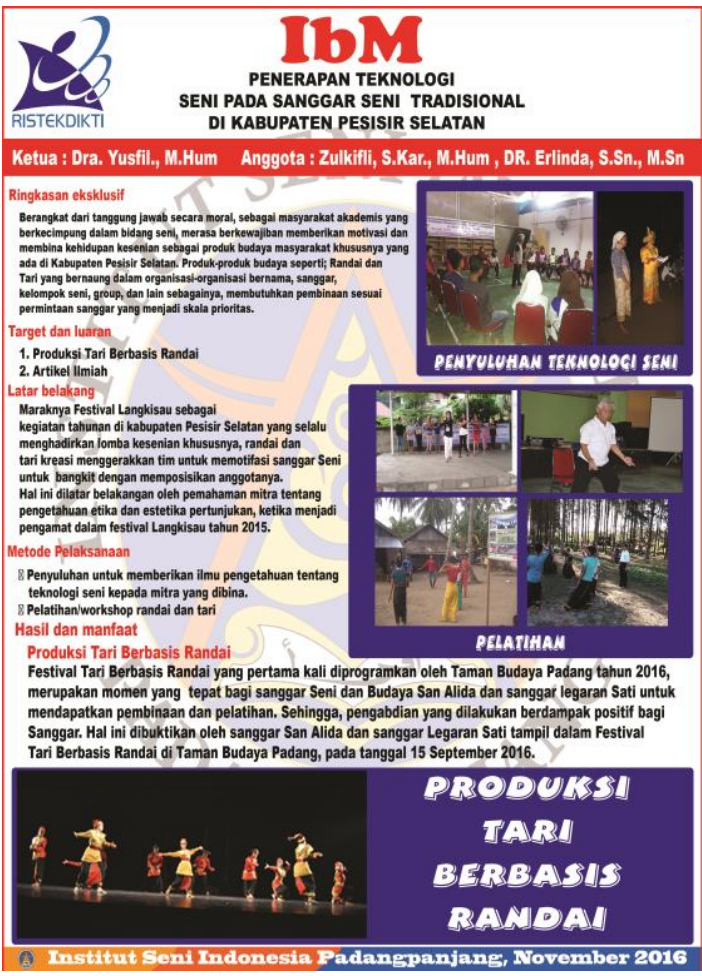


FILOSOFI "BATOBOH": Dalam masyarakat Minangkabau upacara-upacara yang dilakukan sebelum mendirikan bangunan baik Rumah Gadang maupun Balairung (Balai Adat) serta bangunan lainnya yang dikenal dengan beberapa upacara yang disebut dengan batoboh. Batoboh berasal dari kata Taboh yang artinya menebang atau mengambil sesuatu, jadi dengan mengambil kayu dihutan sebagai bahan utama dalam membangun rumah dan bangunan lainnya. Upacara Batoboh ini sangat bermanfaat bagi masyarakat Minangkabau yaitu dapat meningkatkan Gotong-Royong dan solidaritas antar sesama suku Minangkabau karena memberi kesempatan kepada kerabat-kerabat untuk terlibat dalam pembangunan rumah serta bangunan lain.

Alamat Redaksi: LPPMPP ISI Padangpanjang Jalan Bahder Johan Padangpanjang 27128 Sumatera Barat Telp. (0752) 485466, Fax.(0752) 82803 e-mail: batoboh@gmail.com

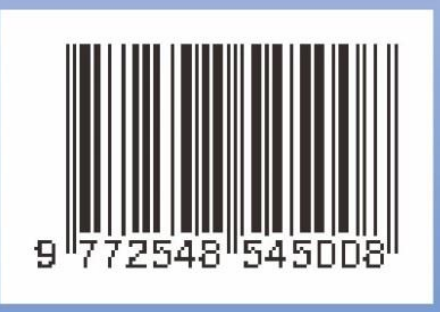

